\title{
The timing of chemotherapy in multimodality treatment of locally advanced lung cancer: One size does not fit all
}

\author{
Alessandro Brunelli, MD \\ From the Department of Thoracic Surgery, St James's University Hospital, Leeds Teaching Hospital NHS Trust, \\ Leeds, United Kingdom. \\ Disclosures: Author has nothing to disclose with regard to commercial support. \\ Received for publication Sept 25, 2018; accepted for publication Sept 26, 2018; available ahead of print Nov 3, \\ 2018. \\ Address for reprints: Alessandro Brunelli, MD, Department of Thoracic Surgery, St James's University Hospital, \\ Bexley Wing, Beckett St, Leeds, LS9 7TF, United Kingdom (E-mail: alexit_2000@yahoo.com). \\ J Thorac Cardiovasc Surg 2019;157:754-5 \\ $0022-5223 / \$ 36.00$ \\ Copyright (c) 2018 by The American Association for Thoracic Surgery \\ https://doi.org/10.1016/j.jtcvs.2018.09.101
}

In patients with large primary lung cancer or positive nodal disease, the timing of chemotherapy with respect to surgery remains a matter of debate. The study by Brandt and colleagues ${ }^{1}$ is an elegant retrospective analysis on a specific subset of these patients, those with cT2-4 N0-1 non-small cell lung cancer. Although most of the studies focused on adjuvant chemotherapy in this setting, induction chemotherapy remains appealing for several reasons, including treatment of micrometastases and ability to assess treatment response, which may lead to modifying or stopping the therapy or informing appropriate selection of additional adjuvant therapies. This is becoming even more important with the increasing role of induction immunotherapy and the use of major pathologic response as the primary end point of efficacy studies. ${ }^{2}$

Brandt and colleagues ${ }^{1}$ found a similar effect of neoadjuvant and adjuvant cisplatin-based chemotherapy on diseasefree survival and overall survival. ${ }^{1}$ This is not a completely new finding ${ }^{3,4}$; however, it is based on robust singleinstitution data collected in a clinical database, which is one of the strengths of this analysis because it ensures standardization.

In my opinion, the most attractive feature of neoadjuvant chemotherapy is the increased compliance to systemic treatment. The only randomized trial directly comparing induction versus adjuvant treatment showed that only $67 \%$ of patients were able to complete all planned chemotherapy cycles after surgery versus $90 \%$ in the neoadjuvant arm. In addition, in the neoadjuvant group, only $5.5 \%$ of patients showed progressive disease during treatment. ${ }^{4}$

The results presented in the study by Brandt and colleagues ${ }^{1}$ are reassuring because they show similar survival figures in the 2 groups. Unfortunately, the authors were

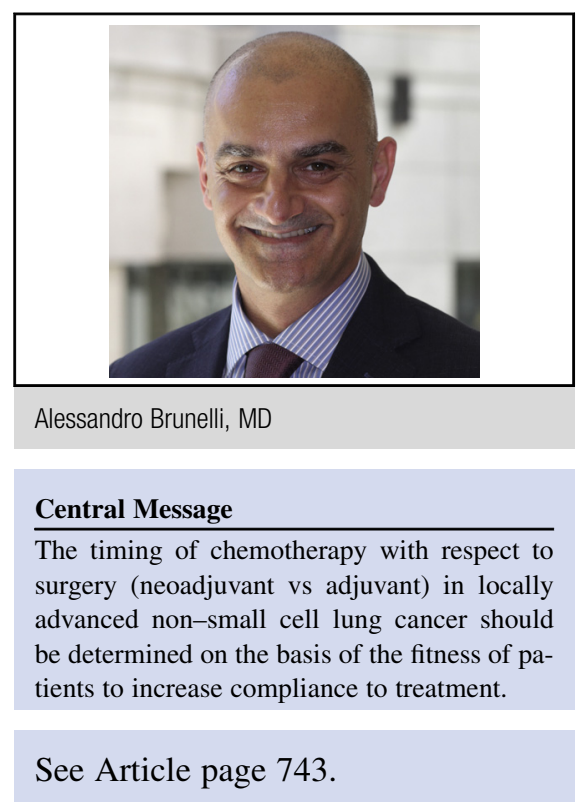

not able to perform an analysis including patients who were not able to receive chemotherapy after surgery or those who showed progressive disease during neoadjuvant chemotherapy and did not receive surgery. The inclusion of these 2 subsets of patients would have certainly added to the meaning of the analysis. In fact, based on previous data, ${ }^{4}$ it is probable that many more patients would have been included in the missed adjuvant group compared with the missed surgery/missed neoadjuvant chemotherapy group, likely increasing the survival benefit in the intention to neoadjuvant treatment group.

Fitness of the patient at the time of diagnosis should be taken into account when deciding the timing of chemotherapy. Previous studies have shown that pulmonary function and quality of life are at their lowest levels 4 weeks after surgery. This is the time when adjuvant chemotherapy is supposed to be started.

A young, fit patient would likely experience an uneventful postoperative course and be able to receive adjuvant chemotherapy. On the other hand, an 80-year-old patient with poor pulmonary function and other underlying comorbidities would probably not be able to tolerate full-dose and timely chemotherapy on top of lung resection. Knowing that the preoperative or postoperative administrations are at least equivalent is reassuring. 
I want to congratulate Dr Brandt and colleagues at Memorial for their timely and important analysis.

\section{References}

1. Brandt WS, Yan W, Zhou J, Tan KS, Montecalvo J, Park BJ, et al. Outcomes after neoadjuvant or adjuvant chemotherapy for cT2-4N0-1 non-small cell lung cancer: a propensity-matched analysis. J Thorac Cardiovasc Surg. 2019; $157: 743-53$
2. Pataer A, Kalhor N, Correa AM, Raso MG, Erasmus JJ, Kim ES, et al. Histopath ologic response criteria predict survival of patients with resected lung cancer after neoadjuvant chemotherapy. J Thorac Oncol. 2012;7:825-32.

3. Lim E, Harris G, Patel A, Adachi I, Edmonds L, Song F. Preoperative versus post operative chemotherapy in patients with resectable non-small cell lung cancer: systematic review and indirect comparison meta-analysis of randomized trials. $J$ Thorac Oncol. 2009; 4:1380-8.

4. Felip E, Rosell R, Maestre JA, Rodríguez-Paniagua JM, Morán T, Astudillo J, et al Preoperative chemotherapy plus surgery versus surgery plus adjuvant chemotherapy versus surgery alone in early-stage non-small-cell lung cancer. J Clin Oncol. 2010;28:3138-45. 